\title{
CHONDROSARCOMA PELVIS, BEYOND THE BOUNDARIES.
}

1. MBBS, FCPS

Associate Professor Orthopedic Surgery

Dow University of Health Sciences/ Civil Hospital Karachi.

2. FRCS

Chairman and Head

Dow University of Health Sciences/ Civil Hospital Karachi.

3. MBBS, FCPS

Assistant Professor Orthopedic Surgery

Dow University of Health Sciences/ Civil Hospital Karachi.

4. MBBS, FCPS

Assistant Professor Orthopedic Surgery

Dow University of Health Sciences/ Civil Hospital Karachi.

5. MBBS, FCPS

Assistant Professor Orthopedic Surgery

Dow University of Health Sciences/ Civil Hospital Karachi.

6. MBBS, FCPS

Assistant Professor

Dow University of Health Sciences/

Civil Hospital Karachi.

\section{Correspondence Address:}

Dr. Badaruddin Sahito

Department of Orthopedic Surgery

Dow University of Health Sciences/

Civil Hospital Karachi.

sahito.badar@hotmail.com

Article received on:

11/09/2019

Accepted for publication:

17/02/2020
Badaruddin Sahito1, Maratib Ali ${ }^{2}$, Dileep Kumar ${ }^{3}$, Nauman Hussain ${ }^{4}$, Noman Parekh ${ }^{5}$, Mohammad Tahir Lakho ${ }^{6}$

ABSTRACT... Objectives: The objective of our study to find the outcome of extensive chondrosarcoma pelvis after surgery. Study Design: Case Series study. Setting: Department of Orthopaedic Surgery Dow University of Health Sciences / Civil Hospital Karachi. Period: From April 2014 to December 2018. Material \& Methods: Seven patients with Chondrosarcoma pelvis included in this study. Results: All Seven patients were male. 2 patient age was in 20's, three in 40's and two in 60's with median age of 44. Clinically presentation of patients was variable. One patient present with groin lump, one with pain and swelling lower abdomen, three with hip pain, one patient with severe gluteal pain and lump, one with massive lump extending from the mid abdomen to groin and urine retention and constipation. Five patients have left pelvis involved and two have right side. Two patients have pubic bone and ischium (Level III) involved, two have ilium (Level I) and three have ilium, acetabulum and pubis (Level I, II, III). Two patients with have preoperatively sciatic nerve palsy. Two patients have medical comorbid. One was asthmatic and one had psychiatric illness. No patient had metastasis at presentation. Pubis and ischium with tumor resected in two cases, partial ilium resection in one case, one complete $\mathrm{P} 1$ resection with sciatic nerve, one patient have internal hemipelvectomy and one patient had internal hemipelvectomy that bone recycled in liquid nitrogen and pelvis re-implanted and fixed with recon plates and hip joint reconstructed with total hip replacement. One patient had external hemipelvectomy due to pus at tumor site. Total duration of surgery in patient having thirteen hours, and remaining have 3 to 5 hours. Blood loss during these surgeries was in between 1000 to $1200 \mathrm{ml}$. Three patients have wound infection, one patient had L5 nerve root injury. Patient with external hemipelvectomy develop wound dehiscence and uro-cutaneous fistula. Two patients died, one with recycled bone after 15 months due cardiac problem and $2^{\text {nd }}$ due to disease related complications within 3 months of surgery. Conclusion: Pelvic chondrosarcoma must be operated by the team of surgeons including orthopaedic surgeon, urologist and general surgeon because of the tumor presents with massive lumps due to unrestricted compartment and can involve the important pelvic organ. With team any complication can be prevented and treated immediately.

Key words: $\quad$ Chondrosarcoma, Hemipelvectomy, Limb Salvage, Pelvis.

Article Citation: Sahito B, Ali M, Kumar D, Rajput NH, Parekh N, Lakho MT. Chondrosarcoma pelvis, beyond the boundaries. Professional Med J 2020; 27(9):2014-2022. DOI: $10.29309 / \mathrm{TPMJ} / 2020.27 .09 .4127$

\section{INTRODUCTION}

After osteosarcoma, the $2^{\text {nd }}$ most common tumor of the bone is chondrosarcoma. ${ }^{1}$ Surgery is the main stay of treatment as chondrosarcoma is chemoradiotherapy resistant. ${ }^{2,3}$ Chondrosarcoma is primary and secondary that occur due to multiple hereditary exostosis, but it is rare. ${ }^{4}$ Chondrosarcoma is a cartilage matrix producing mesenchymal tumor with $20-27 \%$ of primary malignant bone tumor. ${ }^{5}$ There are many types of chondrosarcoma, with variable prognosis. ${ }^{6}$
Enneking and Dunham classified pelvic tumor resection in 1978 as type-I ilium, type-II acetabulum and Type III pubis and ischium. ${ }^{7}$ With advances in tumor surgery limb salvage becomes possible for pelvic tumors with variable methods of reconstruction or without reconstruction. Type I pelvic resection can be reconstructed with autograft or allograft to prevent proximal migration and shortening. ${ }^{8}$ Type $\mathrm{II}$ resection can be reconstructed with flail hip, hip transposition, prosthesis like saddle prosthesis, hemipelvis 
prosthesis, allograft prosthesis composite, modular prosthesis. And reconstruction with ice cream cone prosthesis. ${ }^{9,10,11,12}$ Recently Microwave ablation for pelvic chondrosarcoma showing encouraging result as well. ${ }^{13}$

\section{OBJECTIVES}

The objective of our study to find the outcome of extensive chondrosarcoma pelvis after surgery.

The Rationale of our study is to find out results and problems of multilevel area chondrosarcoma pelvis.

\section{MATERIAL \& METHODS}

This is a Prospective case series study. This study is conducted at department of Orthopaedic surgery Dow University of health sciences/ civil hospital Karachi from April 2014 to December 2018.

Inclusion Criteria

Patients with chondrosarcoma pelvis in all age groups

\section{Exclusion Criteria}

Other Pelvic tumors, Metastatic lesions.

\section{RESULTS}

Seven patients with Chondrosarcoma pelvis included in this study. All Seven patients were male. 2 patient age was in 20's, three in 40's and two in 60's with median age of 44 years. Clinically presentation of patients was variable. One patient present with groin lump, one with pain and swelling lower abdomen, three with hip pain, one patient with severe gluteal pain and lump, one with massive lump extending from the mid abdomen to groin and urine retention and constipation. Five patients have left pelvis involved and two have right side. Two patients have pubic bone and ischium (Level III) involved, two have ilium (Level I) and three have ilium, acetabulum and pubis (Level I, II, III). Two patients with have preoperatively sciatic nerve palsy. Two patients have medical comorbid. One was asthmatic and one had psychiatric illness. As there is no role of chemotherapy and radiotherapy in chondrosarcoma patient so surgery planned after all investigations and workup for metastasis. No patient had metastasis at presentation. Pubis and ischium with tumor resected in two cases, partial ilium resection in one case, one complete $\mathrm{P} 1$ resection with sciatic nerve, one patient have internal hemipelvectomy and one patient had internal hemipelvectomy that bone recycled in liquid nitrogen and pelvis re-implanted and fixed with recon plates and hip joint reconstructed with total hip replacement. One patient had external hemipelvectomy due to pus at tumor site. Total duration of surgery in patient having thirteen hours, and remaining have 3 to 5 hours. Blood loss during these surgeries was in between 1000 to $1200 \mathrm{ml}$. Three patients have wound infection, one patient had L5 nerve root injury. Patient with external hemipelvectomy develop wound dehiscence and uro-cutaneous fistula. Two patients died, one with recycled bone after 15 months due cardiac problem and $2^{\text {nd }}$ due to disease related complications within 3 months of surgery.

In our study patient presented with extensive disease, massive tumor beyond one compartment. Patient with L5 root injury because tumor involving the root, so we cut to achieve tumor free margins and patient who develops fistula his lesion was extending to bladder and buttock that tumor also infected before surgery, that's why he develop complication.

\section{Tumor Excision Procedure}

Utilitarian incision used to open the pelvis. Anteriorly femoral artery, vein and nerve, spermatic cord and bladder spared, sciatic nerve saved posteriorly. Whole pelvis removed in hemipelvectomy patients. Anterior part of incision used for pubic rami tumors and posterior part of incision to remove iliac blade tumor.

\section{Postoperative Rehabilitation}

Patient mobilized on bed on first day with calf and quadriceps strengthening exercise. Stitches removed after two weeks. Skin traction applied in hemipelvectomy patients for three weeks. Partial weight bearing allowed after four weeks and full weight bearing at eight weeks. Patients with pubic and ilium tumors allowed full weight bearing as 
they become pain free. Antibitotics given from one week to three weeks average.

\section{Patient 1.}

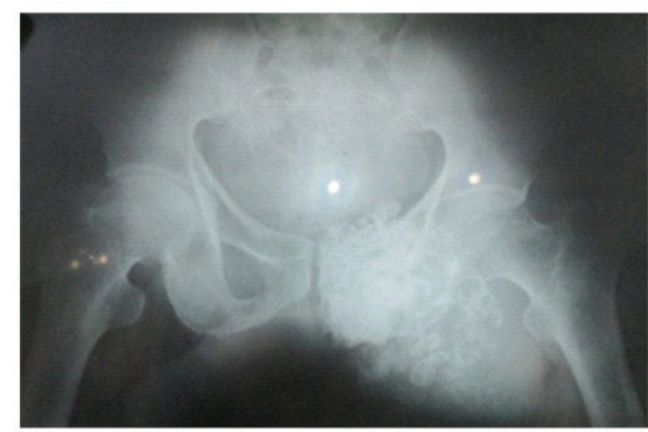

Cauliflower extrapelvic lump pubis \& ischium.

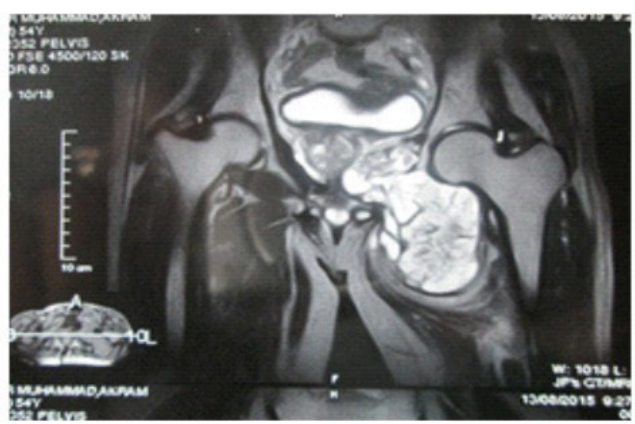

MRI. Hyperintense lesion extend to bladder, medial thigh, crossing midline.

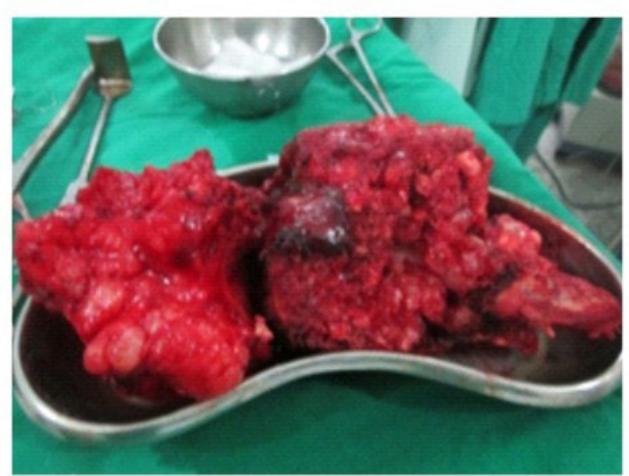

Postop resection; well differentiated chondrosarcoma.

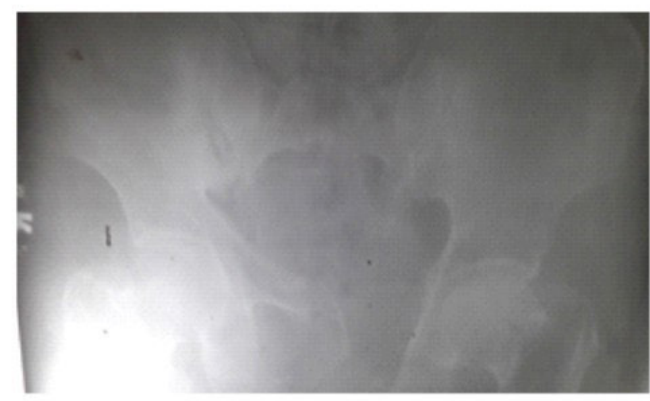

After 5 years opposite pelvis move to operated site.

\section{Patient 2.}

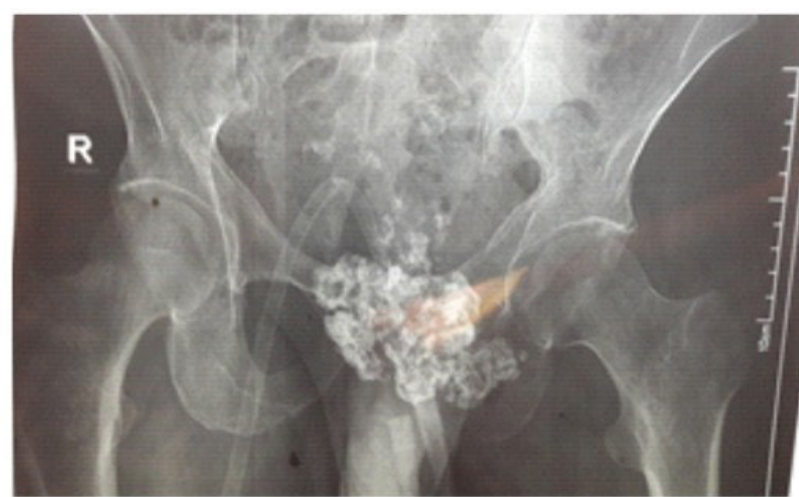

Cauliflower lesion pubic symphysis to left.

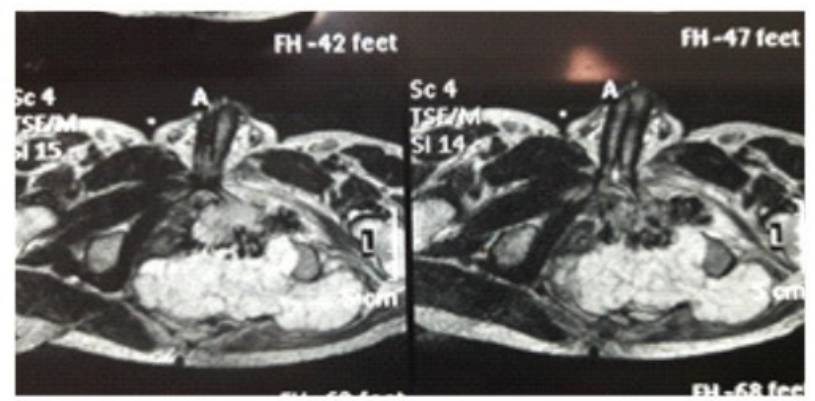

MRI, Hyperintense lesion extend from pubis to posteriorly sacrum.

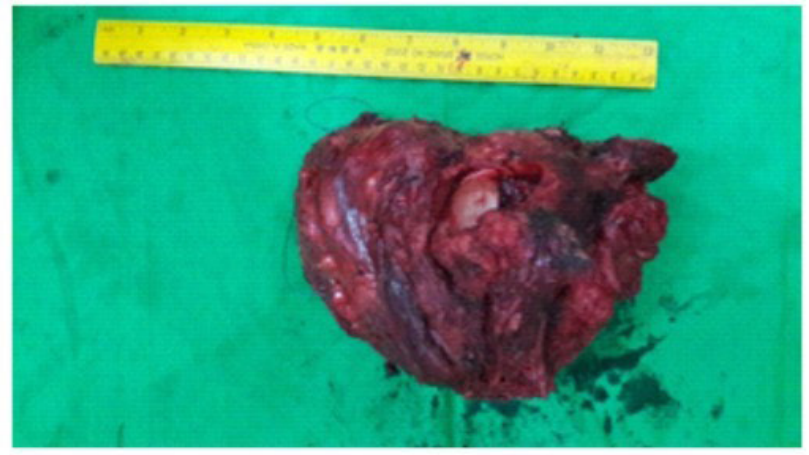

Internal hemipelvectomy, post resection.

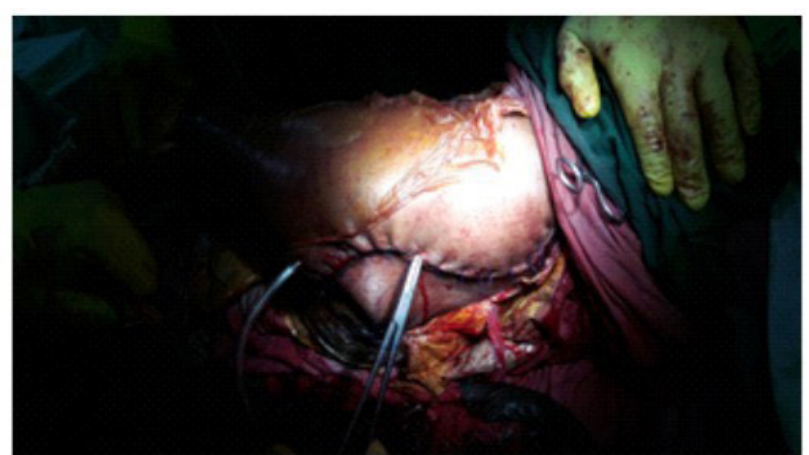

Wound closure. 


\section{Patient 3.}

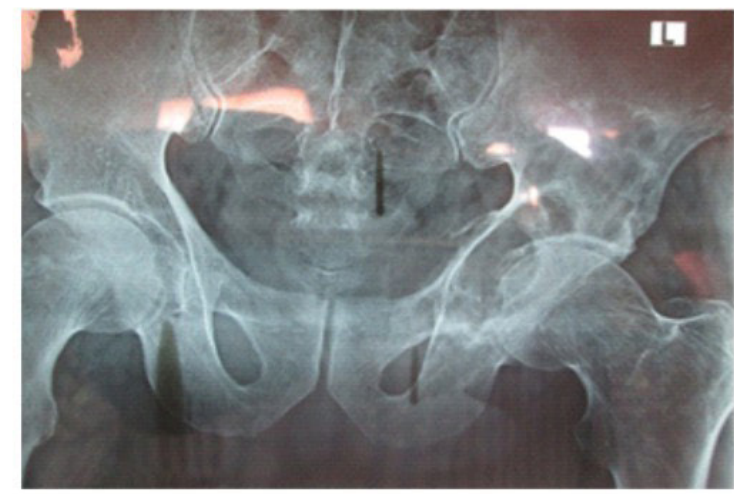

Osteolytic lesion extend to ilium, acetabulum, pubis \& ischium.

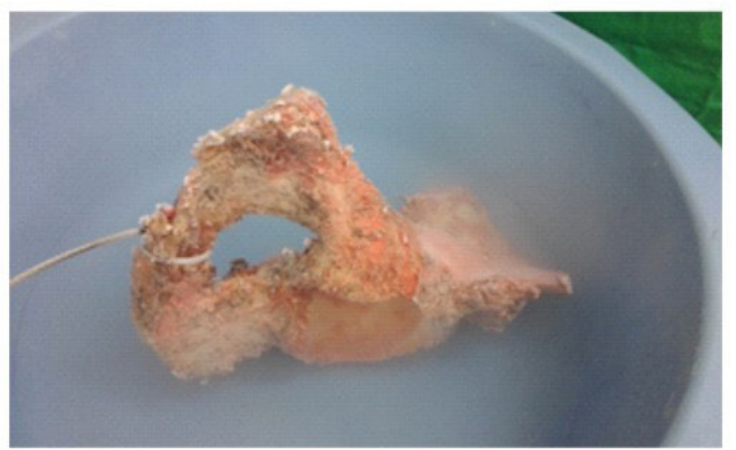

After resection, Bone freeze with liquid nitrogen.

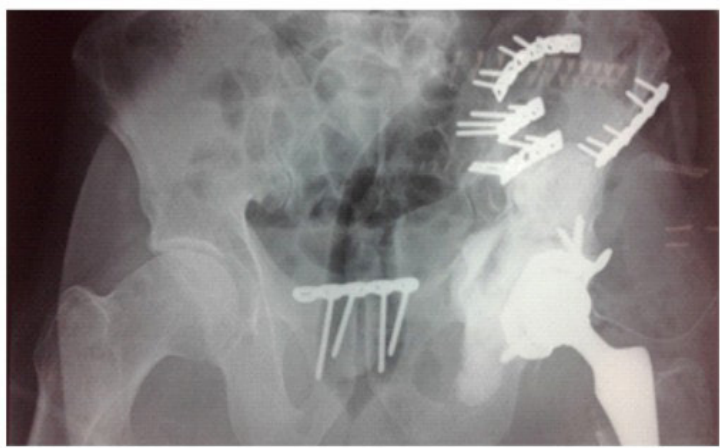

Pelvis re-implanted \& acetabulum reconstructed.

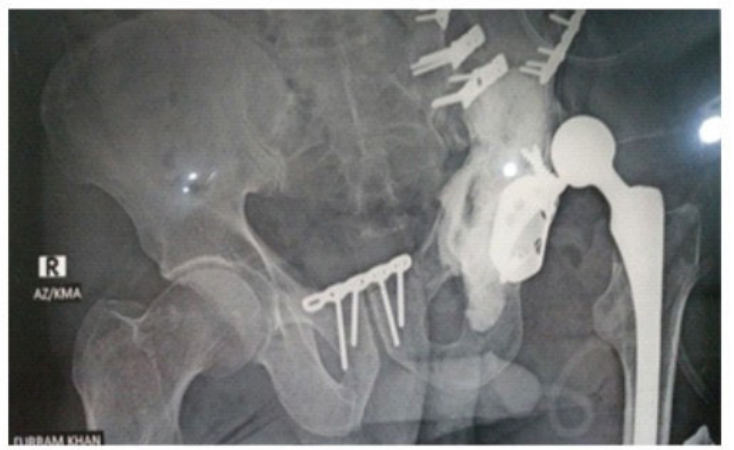

Post op dislocation. Relocated after few days.

\section{DISCUSSION}

A retrospective study of 31 patients of dedifferentiated chondrosarcoma, with mean age of 55.6 years, ilium P1 in $51.6 \%$ and P2 acetabulum with or without other pelvic parts involved. 13 patients treated with palliative and 18 with limb salvage surgery and five with hindquarter amputation. ${ }^{14}$

87 Patients in 32 years period treated with wide margin in $62 \%$, marginal in $36 \%$ and $2 \%$ patient with residual tumor. 5 years local recurrence free survival was $75 \%$ and overall survival at 5 and 10 years were 79 and $75 \%$. High grade, metastatic and age related to pelvic chondrosarcoma have worse prognosis. ${ }^{15}$

A series of 18 pelvic tumor patients, 8 patient has chondrosarcoma reconstructed with modular pelvic prosthesis and femoral head autograft. Three patients died of tumor, one excluded because of recurrence. ${ }^{7}$

Three patients treated at Sanglalo general hospital; 1 with P1, 2 with P3. Internal hemipelvectomy with non-vascularized fibula reconstruction in P1. It shows good results. ${ }^{16}$

Netherland cancer registry analyzed 2186 patients with chondrosarcoma, showing 3, 5 and 10 year survival of $96 \%, 93 \%$ and $88 \%$ in grade I, $74 \%$ \& $62 \%$ for grade II and $38 \%, 31 \%$ and $26 \%$ grade III chondrosarcoma. They suggest incidence of chondrosarcoma is increasing. ${ }^{17}$

Three thousand seven hundred thirty seven patients of chondrosarcoma analyzed, showing overall survival rate of $73.9 \%$ in five years and patient with distant stage, undifferentiated grade, single radiation have only $30 \% 5$ year survival. ${ }^{18} \mathrm{~A}$ series of 64 patients of localized chondrosarcoma. Thirteen patients had a hemipelvectomy to achieve local tumor control, whereas fifty-one patients underwent a limb-salvage procedure. $19 \%$ had local recurrence, and $17 \%$ had distant metastases. $69 \%$ were alive without evidence of disease, $20 \%$ had died of the disease, $9 \%$ had died of unrelated causes, and $2 \%$ was alive with disease. 


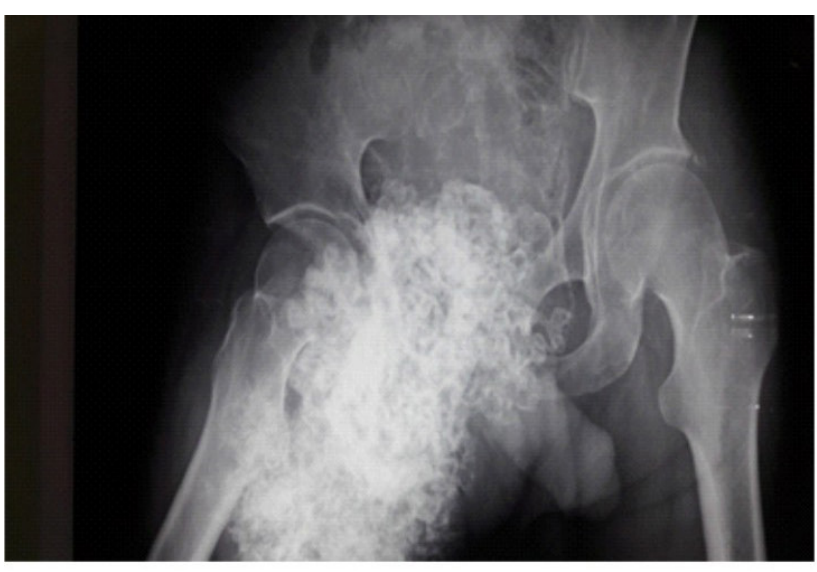

Osteoblastic lesion right thigh, pubis, ischium crosses midline \& abdomen.

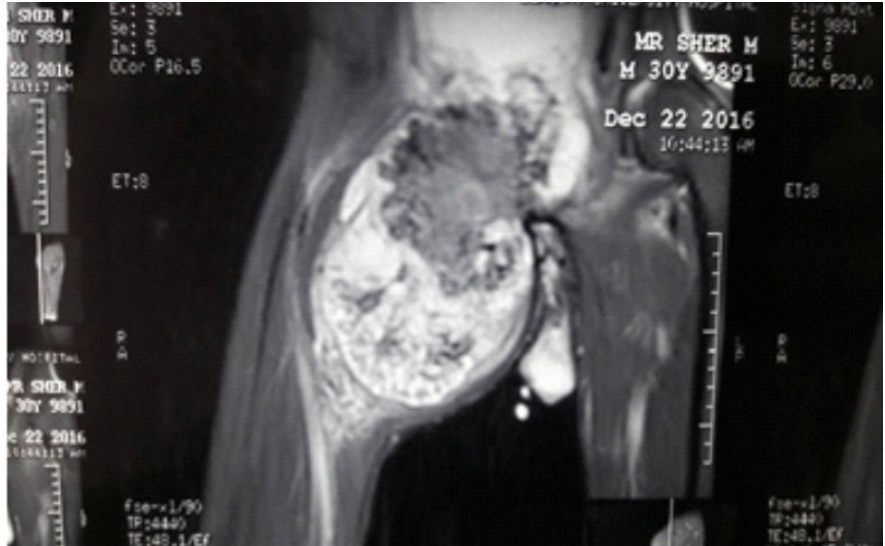

MRI T2- hyperintense lesion extend to abdomen, pelvis proximal two third thigh, displacing femoral artery.

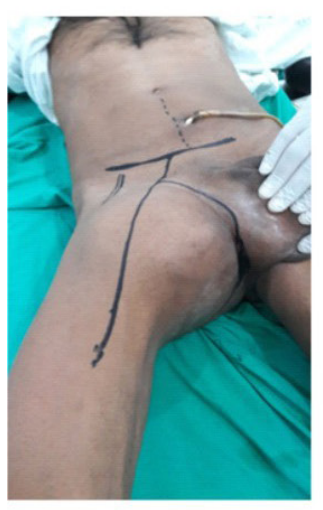

Incision.

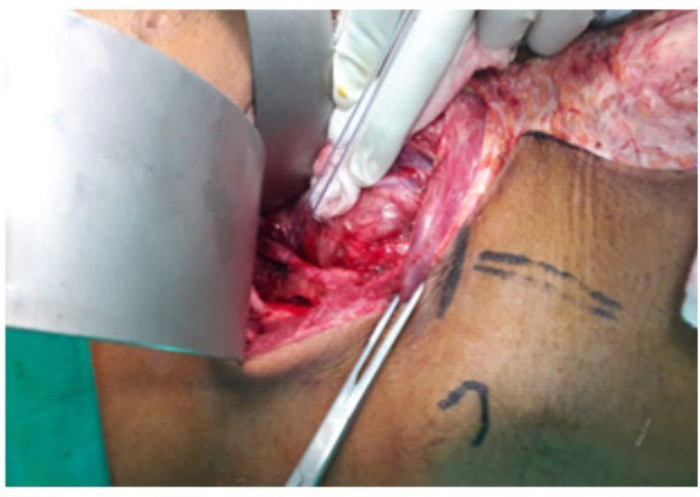

First common iliac artery identified \& hold.

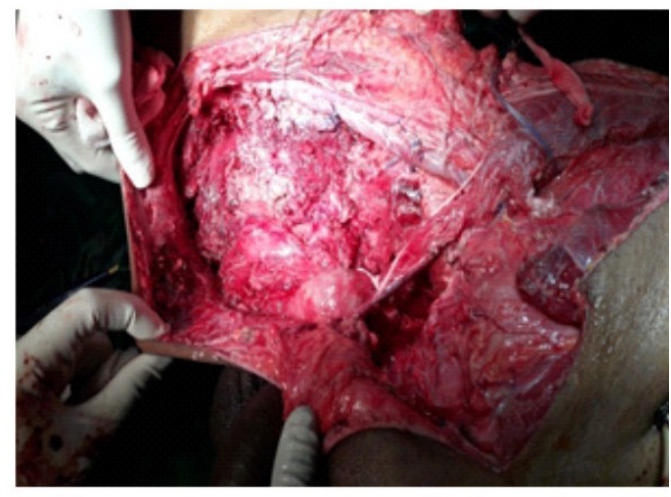

Femoral bundle free from tumor.

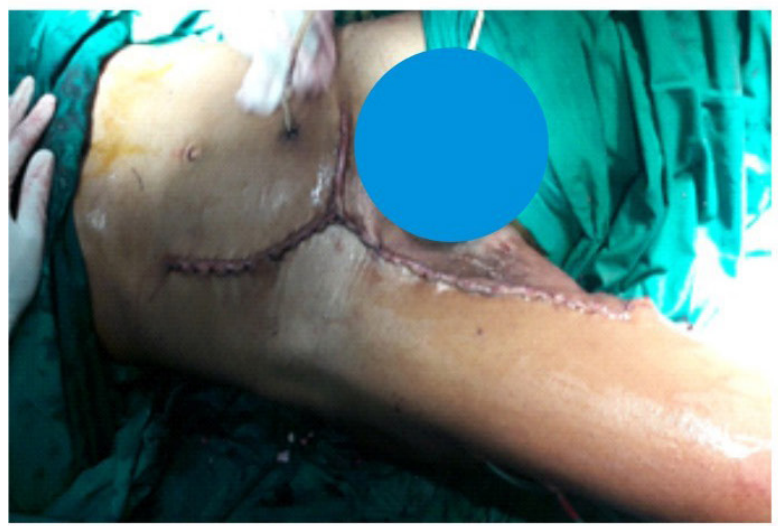

Wound closure.

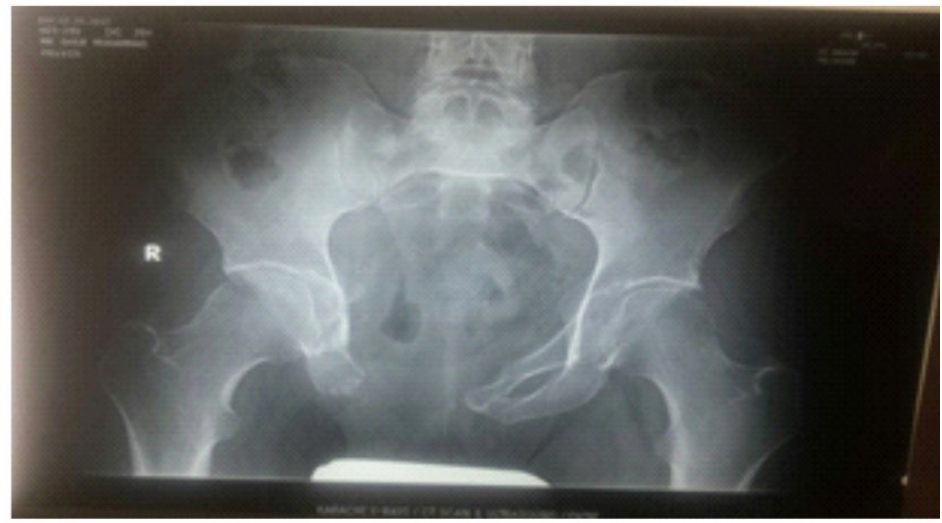

Post resection.

\section{Patient-4.}

Grade I Chondrosarcoma

Less than a wide surgical margin correlated with local recurrence $(p=0.014)$. High-grade tumors correlated with poor overall survival ( $p<0.001$ ). Patients treated with limb-salvage procedure were able to walk with MSTS of $77 \% .{ }^{19}$

Five patients with periacetabular chondrosarcoma treated with hemipelvectomy were walking with \& without support after three to six years with no recurrence. ${ }^{20}$

In a 40year study 113 patients at the time of follow-up, forty patients were alive and seventythree were dead. 


\section{Patient 5.}

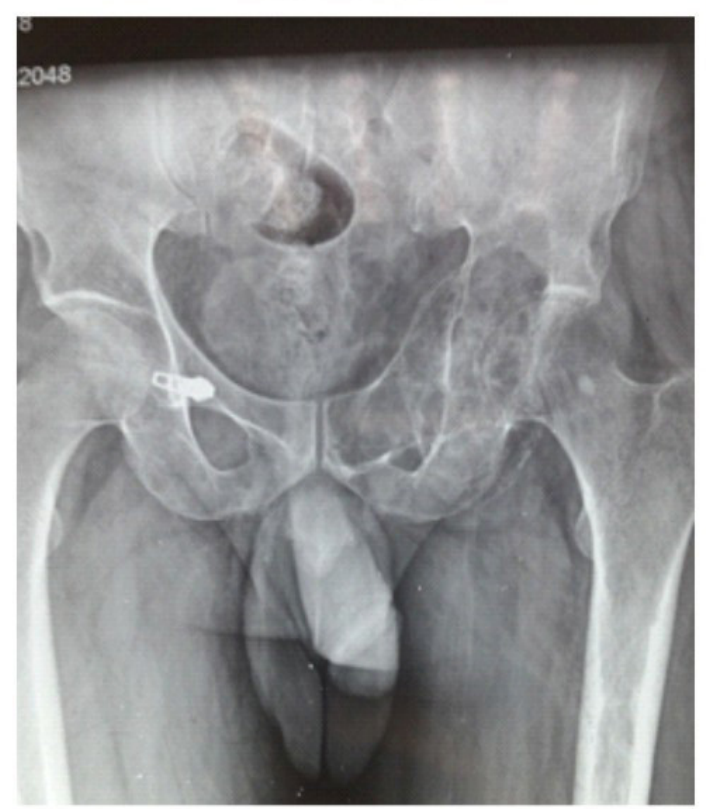

Osteolytic lesion Extending to I,II,III level.

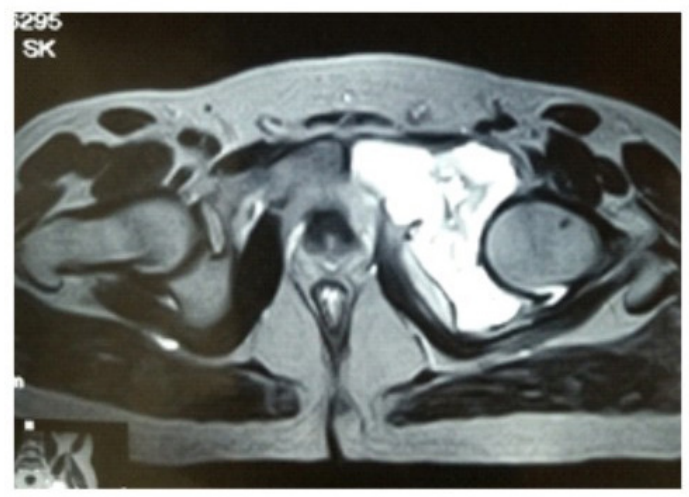

T2 MRI hyperintense lesion, extend to soft tissue.

External hemipelvectomy done

First biopsy chondroid neoplasm, second biopsy showed well differentiated chondrosarcoma

Patient 6.

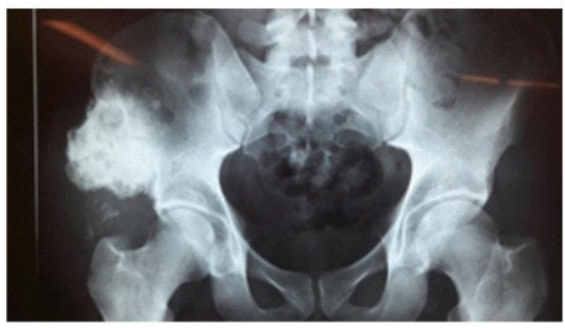

Osteoblastic lesion ilium.

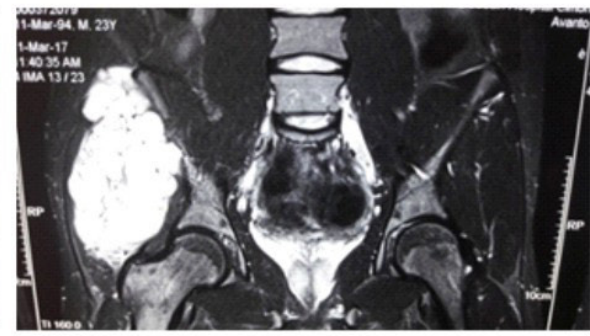

T2 MRI- extending to abductors to greater trochanter from ilium.

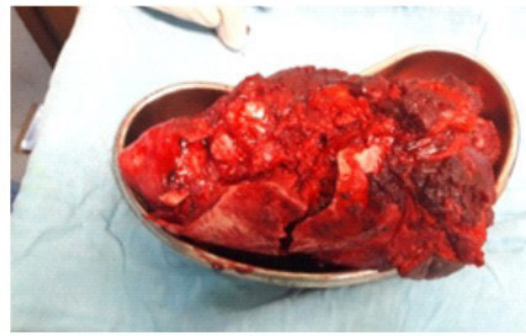

Post Resection.

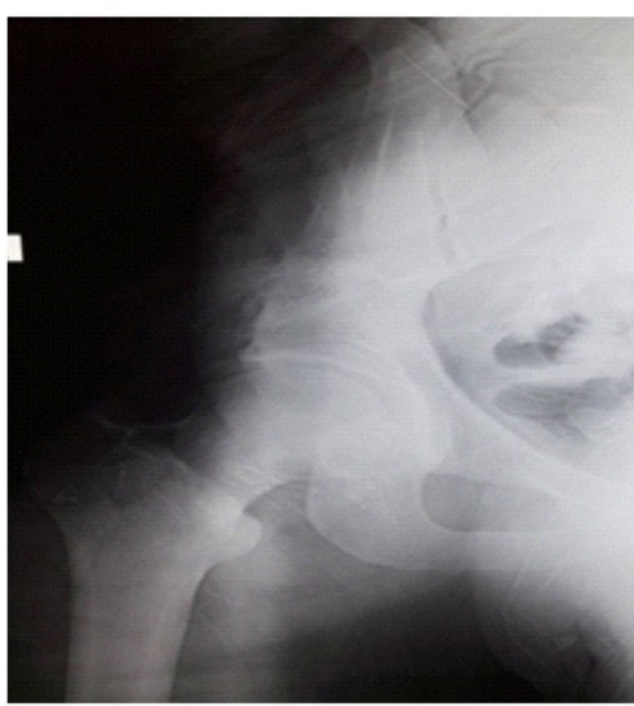

Postop X-Ray

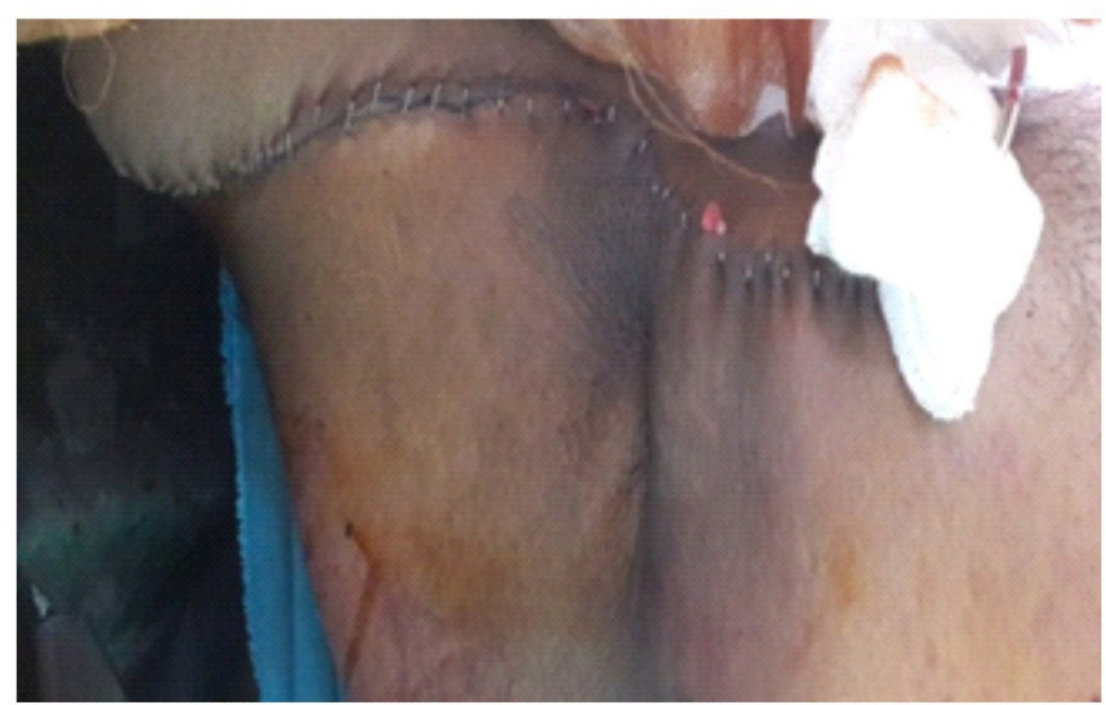

Wound Closure 
Wide margin resection and the histological grading is the most important prognostic factors. ${ }^{21}$

The 227 patients of chondrosarcoma, out of that 51 were pelvic tumors. The remaining three patients had an amputation. Patients treated with wide margins had prolong survival than with marginal or an intralesional resection $(p<0.04) .{ }^{22}$

From 1970 to 1985, at the Mayo Clinic, sixty pelvic tumor patients treated with limb salvage with wide margin for a primary malignant tumor of the pelvis followed by reconstruction with arthrodesis if satisfactory margins can be achieved by the excision of a pelvic tumor, salvage of the limb is justified from both an oncological and a functional standpoint. ${ }^{23}$

110 patients with pelvic sarcoma with 40 chondrosarcomas treated with and without pelvic reconstruction. Hemi-pelvic mega prosthesis, allograft, autograft, hip transposition and hindquarter amputations done. Complications were infection, leg length discrepancy, noted in mostly. ${ }^{24}$

A review of Navigation dependent resection of pelvic tumors done on 15 patients, all resected specimen had free tumor margins that suggest it is more accurate and useful in tumor surgery. ${ }^{25}$

A case report of two chondrosarcoma patient treated with resection and reconstruction with Charlney total hip replacement reinforced with Kuntscher rods and wires. Both patients had good functional outcome. So this procedure can be done in selected patients. ${ }^{26}$

42 chondrosarcoma patients analyzed retrospectively found $64 \%$ five to ten years survival. 16 patients died, 12 because of disease and 4 of unknown reason. 11 patients develop metastasis within twelve months after surgery. Centrally localized tumor worse survival than peripheral. $18 \%$ recur in mean period of 24 months. Results were worse in patients with dedifferentiated chondrosarcoma and stage III tumors. ${ }^{27}$

Grade I chondrosarcoma treatment is controversial. Retrospective study of 80 patients treated with intralesional resection with increased local recurrence but no influence on overall survival or on the metastasis. Patients treated with wide margin resection had no recurrence. Intralesional resection should be avoided because of $100 \%$ recurrence in pelvic tumors. ${ }^{28}$

The strength of pelvic tumor resection patient are we able to remove tumor with marginal and wide margin resection, no residual tumor left behind in tumors extending beyond the compartment. The limitation of our study are small sample size and higher infection due to extensive disease and prior infected tumor in one patient.

\section{CONCLUSION}

Pelvic chondrosarcoma must be operated by the team of surgeons including orthopaedic surgeon, urologist and general surgeon because of the tumor presents with massive lumps due to unrestricted compartment and can involve the important pelvic organ. With team any complication can be prevented and treated immediately.

Copyright 17 Feb, 2020.

\section{REFERENCES}

1. Sekito S, Kato M, Nishikawa K, Yoshio Y, Kanai M, Kanda $H$, Arima KSugimura Y. Successfully treated lung and renal metastasis from primary chondrosarcoma scapula with radiofrequency ablation and surgical resection. Case report in oncological medicine 2019; 1-5.

2. Gelderblom H, Hogendoorn PCW, dijikstra et al. The clinical approach towards chondrosarcoma; oncologist 2008; 13;3;320-329.

3. Etchebehre M, Camergo P, Croci AT, Oliveira CR, Baptista AM. Relationship between surgical procedure and outcome for patients with grade 1 chondrosarcoma. Clinics 2005; 60; 2; 121-126.

4. Lukas Nystrom M, Barry DeYoung R. Jose Morcuende A. Secondary chondrosarcoma of the pelvis arising from a solitary exostosis in an 11-year-old patient. The lowa Orthopaedic Journal. 2013;33:213-16.

5. Ye C, Luo Z, Zeng J, Dai M. Chondrosarcoma of the patella. A case report. Medicine 2017; 96; 37;1-5. 
6. Ishida, Yamamoto T, Goto M, Kawano H, Yamamoto A, Machinami R. Clear cell chondrosarcoma of the pelvis in a skeletally immature patient. Skeletal Radiol 1999, 28: 290-293.

7. Huayi Qu, Dasen Li, Shun T, Jic Z, Yifei W, Wei G. Pelvic reconstruction following resection of tumor involving the whole ilium and acetabulum. J B Oncolgy 2019; $16 ; 100 ` 234 ; 1-5$.

8. Lin P, Shao Y, Lu H, Zhang Z, Lin H, Wanh S, Li B, Li $H$, Wang $Z$, Lin $N$, Ye $Z$. Pelvic reconstruction with different rod screw systems following Enneking I/ Iplus IV resection: A clinical study. Oncotarget 2017; 13; 89240; 38978-89.

9. Guo Z, Li J, Pei GX, Li XD, Wang Z. Pelvic reconstruction with a combined hemipelvic prostheses after resection of primary malignant tumor. Surg oncol 2010; 19(2):95-105.

10. Perry KI, Abdel MP, Lewallen DG, Rose PS, Sim FH. Innovative methods of reconstruction after pelvic tumor resection. Curr Surg Rep (2014) 2:41

11. Traub F, Andreou D, Niethard M, Tiedke C, Werner M, Tunn $\mathrm{P}$. Biological reconstruction following the resection of malignant bone tumors of the pelvis sarcoma Vol:2013, ID 745360, 1-7. doi.org/10.1155/2013/745360

12. Fischer NE, Grimer RJ, Jevs L, Abudu A, Carter S. Ice-cream cone reconstruction of the pelvis: a new type of pelvic replacement-early results and lessons learned. J Bone Joint Surg (Br) 2011; 93-B; 684-8.

13. Fan QY, Zhou Y, Zhang M, Ma B, Yang T, Long H, Yu Z, Li Z. Microwave ablation of primary malignant pelvic bone tumors. Frontier Surg; 2019; 6; 5;1-15.

14. Lex JR, Evans S, Stevenson JD, Parry M, Jeys LM, Grimmer RJ. Dedifferentiated chondrosarcoma of the pelvis: clinical outcomes and current treatment. Clin sarcoma Res 2018; 8;23;1-9.

15. Fromm J, Klein A, Baur - Melnyk A, Kndsel T, Linder L, Birkenmaier C, Roder F, Jansson V, Durr HR. Survival and prognostic factors in conventional central chondrosarcoma. Cancer 2018; 18:849:1-10.

16. Wirtanaya GE, Wirabhawa M, Sandiwidayat KS, Aakash. Operative management of chondrosarcoma in pelvic region. Case series. Int J Res Med Sc. 2019; Feb 7(2): 619-623.

17. van Praag VM, Rueten-Budde AJ, Ho V, Dijkstra PD, van der Geest IC, Bramer JA, Schaap GR, Jutte PC, Schreuder HB, Ploegmakers JJ, Fiocco M. Incidence, outcomes and prognostic factors during 25 years of treatment of chondrosarcomas. Surgical oncology. 2018 Sep 1;27(3):402-8.
18. Nie Z, Lu Q, Peng $H$. Prognostic factors for patients with chondrosarcoma: A survival analysis based on the Surveillance, Epidemiology, and End Results (SEER) database (1973-2012). Journal of bone oncology. 2018 Nov 1;13:55-61.

19. Pring ME, Weber KL, Unni K, Sim FH. Chondrosarcoma of the pelvis: A review of sixty four cases. J Bone Joint Surg Am, 2001Nov; 83(11):1630-1642.

20. Steel HH. Partial or complete resection of the hemi pelvis. An alternative to hindquarter amputation for peri-acetabular chondrosarcoma of the pelvis. J Bone Joint Surg Am, 1978 sept; 60(6):719-730.

21. Marcove RC, Mike V, Hutter RVP, Huvos AG, Shoji H, Miller TR, Kosloff R. Chondrosarcoma of the pelvis and upper end of the femur. An analysis of factors influencing survival time in one hundred and thirteen cases. J Bone Joint Surg Am, 1972 Apr; 54 (3): 561 -572

22. Lee FY, Mankin HJ, Fondren G, Gebhardt M, Springfield DS, and Rosenberg A, Jennings C. Chondrosarcoma of bone: An assessment of outcome. J Bone Joint Surg Am, 1990Mar; 81(3):326-38.

23. O'Connor, Sim FH. Salvage of the limb in the treatment of malignant pelvic tumors. J Bone Joint Surg Am, 1989 Apr; 71 (4): 481-494.

24. Hillmann A, Hoffmann C, Gosheger G, Rödl R, Winkelmann $\mathrm{W}$, Ozaki T. Tumors of the pelvis: complications after reconstruction. Archives of orthopaedic and trauma surgery. 2003 Sep 1;123(7):3404.

25. So TY, Lam YL, Mak KL. Computer-assisted navigation in bone tumor surgery: seamless workflow model and evolution of technique. Clinical Orthopaedics and Related Research®. 2010 Nov 1;468(11):2985-91.

26. J T Johnson. Reconstruction of the pelvic ring following tumor resection. J Bone Joint Surg Am, 1978 Sep; 60 (6): 747 -751.

27. Bruns J, Elbracht M, Niggemeyer O. Chondrosarcoma of bone: an oncological and functional follow-up study. Annals of oncology. 2001 Jun 1;12(6):859-64.

28. Streitbürger $A$, Ahrens $H$, Balke $M$, Buerger $H$, Winkelmann W, Gosheger G, Hardes J. Grade I chondrosarcoma of bone: the Münster experience. Journal of cancer research and clinical oncology. 2009 Apr 1;135(4):543-50. 


\begin{tabular}{|c|c|c|c|}
\hline \multicolumn{4}{|c|}{ AUTHORSHIP AND CONTRIBUTION DECLARATION } \\
\hline Sr. \# & Author(s) Full Name & Contribution to the paper & Author(s) Signature \\
\hline 1 & Badaruddin Sahito & Conception and design. & Belasefanth \\
\hline 2 & Maratib Ali & $\begin{array}{l}\text { Final approval \& Guarator of } \\
\text { article. }\end{array}$ & \\
\hline 3 & Dileep Kumar & $\begin{array}{l}\text { Collection \& Assembly of } \\
\text { data. }\end{array}$ & \\
\hline 4 & Nauman Hussain & Drafting of article. & \\
\hline 5 & Noman Parekh & Critical review of article. & \\
\hline 6 & Mohammad Tahir Lakho & $\begin{array}{l}\text { Analysis \& interpretation of } \\
\text { data. }\end{array}$ & $\Leftrightarrow=-1$ \\
\hline
\end{tabular}

